\title{
ANALISA PERHITUNGAN POMPA SIRKULASI WWTP LIMBAH PADA AREA PAINTING STEEL DI PT CAKRA INDOPAINT CEMERLANG”.
}

\author{
Ahmad Sufyan, ir.Didit Sumardiyanto, MT \\ Fakultas Teknik Mesin Universitas 17 Agustus 1945 Jakarta
}

\begin{abstract}
Abstrak
Tujuan dalam analisa perhitungan pompa sirkulasi wwtp ini untuk mengetahui dan menentukan spesifikasi pompa yang dibutuhkan pompa seberapa besar daya pompa yang dipakai untuk mensirkulasikan air di area painting steel dengan menghitung spesifikasi pompa yang dipakai, kemudian membandingkan dengan perhitungan teoritis.

Dari hasil perhitungan data yang didapat secara teoritis sebagai berikut : Head teoritis adalah sebesar 12,017 m sedangkan yang ada dilapangan sebesar $25 \mathrm{~m}$ yang dihitung dengan kapasitas yang sama $0,25 \mathrm{~m} / \mathrm{min}$, dan daya motor penggerak teoritis $1,87 \mathrm{~kW}$ sedangkan yang terpasang dilapangan $12 \mathrm{~kW}$.
\end{abstract}

Kata kunci: Head pompa, Daya air $(P w)$.

\begin{abstract}
Interest in the calculation analysis WWTP circulation pump is to examine and determine the specifications of the required pump pump how much power pump used to circulate the water in the area of steel painting by calculating specification pump used, then compared with theoretical calculations.

From the calculation of the data obtained theoretically as follows: Head theoretical amounted to $12.017 \mathrm{~m}$ while the existing field of $25 \mathrm{~m}$ is calculated with the same capacity of $0.25 \mathrm{~m} / \mathrm{min}$, and the theoretical power of $1.87 \mathrm{~kW}$ motor installed while the field $12 \mathrm{~kW}$. Keywords: Head pump, water power $(\mathrm{Pw})$.
\end{abstract}




\section{PENDAHULUAN}

Di dalam proses painting atau pengecatan yang diakukan di PT CAKRA INDOPAINT CEMERLANG baik untuk pengecatan plastik atau untuk pengecatan steel, di dalam proses tersebut ada limbah dari proses pengecatan tersebut. Limbah air yang berada di dalam ruang booth painting disirkulasikan menggunakan pompa yang melewati suatu pipa fluida dari dalam booth painting kebak penampung. Limbah yang ada dibak penampung ini yang kemudian akan disirkulasikan lagi ke dalam ruangan booth painting.

Setiap seminggu sekali dilakukan maintenance atau cleaning machine, air limbah yang di dalam booth harus dikuras atau dikeringkan. Namun pada saat mensirkulasikan air kebooth painting terkadang sering terhambat dan agak lama tidak seperti biasanya. Karena itu pompa sangat penting dalam proses sirkulasi pada painting terutama untuk mengangkut air.

Karena sering terjadi kejadian seperti itu penulis ingin mengetahui dengan menghitung pompa yang ada untuk menentukan pompa yang dilakukan apakah sudah sesuai dengan spesifikasinya ataukah mungkin ada faktor lain yang menjadi hambatan di dalam aliran pipa mungkin juga daya pompa atau head total pompa kecil.

\section{Landasan teori}

\subsection{Wastewater Treatment Plant}

Wastewater treatment plant adalah metode pembenahan dan pengolahan limbah yang difungsikan untuk mengolah air dari kualitas air baku (influent) yang tercemar agar mendapatkan kualitas air pengolahan (effluent). Limbah sebagai suatu sampah yang berbentuk cairan yang merupakan out put dari proses rumah perindustrian yang harus diolah terlebih dahulu sebelum disalurkan ke perairan.

Metode alternative wastewater treatmet plant merupakan pengolahan air limbah dengan peralatan instalasi misalnya dilakukan dengan instalasi pengolahan limbah (IPL) yang mengarah kepda pengolahan yang bersifat mekanis ataupun kimiawi yang mengikutsertakan pemurnian air, baik suspense organic maupun anorganik.

\subsection{Pompa sentrifugal}

Pompa sentrifugal adalah suatu mesin kinetis yang mengubah energi mekanik menjadi energi fluida menggunakan gaya sentrifugal (Sularso, 
2004), pompa sentrifugal terdiri dari sebuah impeller yang berputar di dalam sebuah rumah pompa (Casing). Pada rumah pompa dihubungkan dengan saluran hisap dan saluran keluar. Sedangkan impeller terdiri dari sebuah cakram dan terdapat sudu-sudu, arah putaran sudu-sudu itu biasanya dibelokkan ke belakang terhadap arah putaran.

Bila kipas berputar dengan cepat, maka sudu-sudu kipas memberikan gerak berputar kepada zat cair yang berada di dalam rumah pompa. Gaya sentrifugal yang terjadi mendorong zat cair ke bagian keliling sebuah luar kipas dan terkempakan keluar. Karena itu pada lubang saluran masuk ke dalam kipas di dalam rumah pompa timbul ruang kosong sehingga tekanannya turun (hampa udara). Oleh sebab itu cairan dapat terdorong masuk ke dalam rumah pompa atau terjadi kerja isap. Pada keliling sebelah luar kipas, zat cair mengalir dalam rumah pompa dengan tekanan dan kecepatan tertentu. Zat cair mengalir sedemikian rupa dalam aliran yang tidak terputus-putus dari saluran isap melalui pompa ke saluran kempa.

Jurnal Kajian Teknik Mesin

Vol. 2 No. 1 April 2017

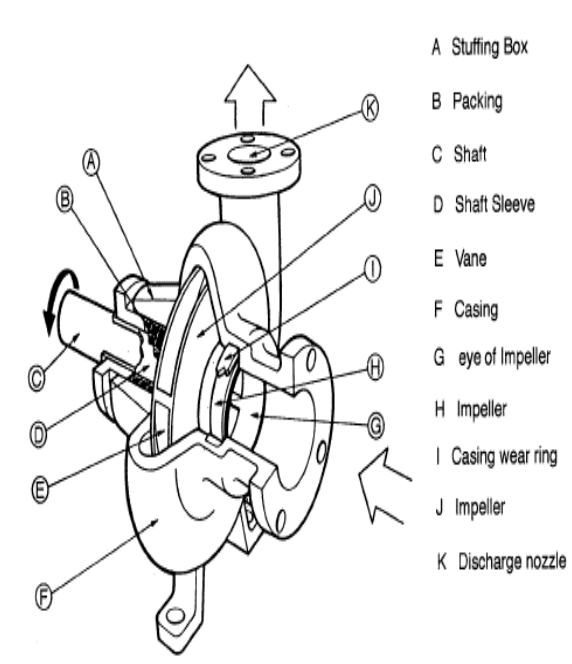

\section{Gambar 2.4 Bagian-bagian pompa sentrifugal}

\subsection{Head Total Pompa}

Head total pompa adalah energi persatuan berat yang harus disediakan oleh pompa untuk mengatasi energi tekanan, kecepatan, perbedaan ketinggian, kerugian gesek dan kerugian-kerugian pada perlengkapan seperti Katup (valve), belokan (elbow), penampang dan lain-lain.

Head Total pompa dinyatakan sebagai berikut:

$\mathrm{H}=h_{a}+\Delta h_{p}+h_{1}+\frac{v_{d^{2}}}{2 g}$

Dimana :

$\mathrm{H}=$ Head Total Pompa(m)

$h_{a}=$ head statis $(\mathrm{m})$ 
$\Delta \mathrm{hp}=$ perbedaan head tekanan yang bekerja pada kedua permukaan fluida (m)

$$
\Delta h_{p}=h_{p_{2}}-h_{p_{1}}
$$

$\mathrm{hl}=$ berbagai kerugian head. Dimana $h_{1}$ $=h_{1 d}+h_{1 s}$ adalah kerugian head gesek pipa keluar dan hls kerugian head gesek pipa masuk.

$\frac{v_{d^{2}}}{2 g}=$ head kecepatan keluar (m)

$\mathrm{g}=$ percepatan gravitasi $(9,8 \mathrm{~m} / \mathrm{s} 2)$

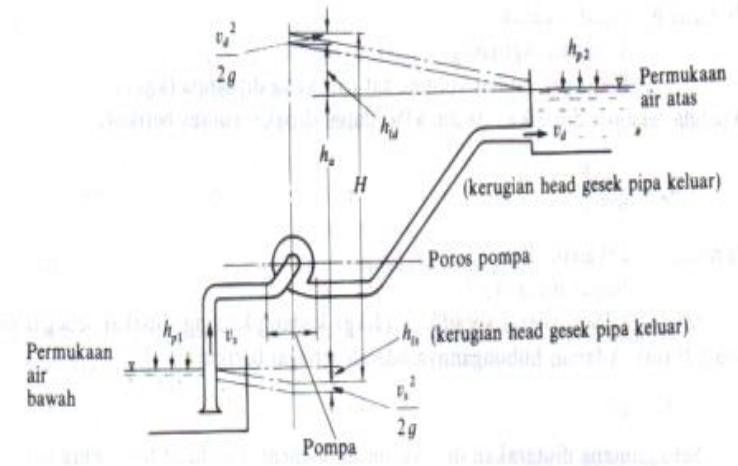

Gambar 2.9 Head pompa

( Sularso Haruo Tahara,p.27 )

Adapun hubungan antara tekanan

dan head tekanan dapat diperoleh dari rumus

$h_{p}=10 \times \frac{p}{\gamma}$

Dimana :

Hp = Head Tekanan $(m)$

$\mathrm{P}=$ Tekanan $(\mathrm{kgf} / \mathrm{cm} 2)$ $\gamma=$ Berat persatuan volume zat cair yang dipompa $(\mathrm{kgf} / \mathrm{l})$

Apabila tekanan diberikan pada $\mathrm{kPa}$,dapat menggunakan rumus sebagai berikut:

$h_{p}=\frac{1}{9,8} \frac{p}{\rho}$

Dimana:

$\mathrm{P}=$ Tekanan $(\mathrm{pa})$

$\rho=$ Rapat massa $(\mathrm{kg} / \mathrm{l})$

Menurut ISO ,energi spesifik $\mathrm{Y}(\mathrm{J} / \mathrm{kg})$ kadang-kadang dipakai sebagai pengganti head $H(\mathrm{~m})$,Adapun hubungannya sebagai berikut :

$Y=g H$

Sebagaimana diutarakan diatas,untuk menentukan head total yang harus disediakan pompa,perlu dihitung lebih dahulu head kerugian $h_{1}$. Dibawah ini akan diuraikan cara menghitung kerugian head tersebut.

\subsection{Head kerugian}

Head kerugian(yaitu head untuk mengatasi kerugian-kerugian) terdiri atas head kerugian gesek didalam pipa-pipa dan head kerugian didalam belokan-belokan, reduser, katup-katup, dsb. 


\subsubsection{Head kerugian gesek dalam pipa}

Untuk menghitung kerugian gesek dalam pipa dapat dipakai rumus dibawah ini

$$
V=C R^{P} S^{q}
$$

$$
h_{f}=\lambda \frac{L}{D} \frac{v^{2}}{2^{g}}
$$

Dimana :

$\mathrm{V}=$ kecepatan rata-rata aliran didalam pipa

$\mathrm{C}, \mathrm{p}, \mathrm{q}=$ koefisien-koefisien

$\mathrm{R}=$ jari-jari hidrolik $(\mathrm{m})$

$\mathrm{R}=\frac{\text { Luas penampang pipa,tegak lurus aliran }\left(\mathrm{m}^{2}\right)}{\text { Keliling pipa atau saluran yang dibasahi }(m)}$

$\mathrm{S}=$ gradien hidrolik

$\mathrm{S}=\frac{h_{f}}{L}$

$h_{f}=$ Head kerugian gesek dalam pipa

$\lambda=$ Koefisien kerugian gesek dalam pipa

$\mathrm{g}=$ percepatan gravitasi $\left(9,8 \mathrm{~m} / \mathrm{s}^{2}\right)$

$\mathrm{L}=\operatorname{panjang} \operatorname{pipa}(\mathrm{m})$

$\mathrm{D}=\operatorname{diameter} \operatorname{pipa}(\mathrm{m})$

Selanjutnya, untuk aliran yang laminer dan yang turbulen, terdapat rumus yang berbeda. Sebagai patokan apakah suatu aliran itu laminer atau turbulen, dipakai bilangan reynolds :

$$
R_{e}=\frac{v D}{v}
$$

Dimana :

$R_{e}=$ Bilangan reynolds

$\mathrm{V}=$ Kecepatan rata-rata aliran didalam pipa

$\mathrm{D}=$ Diameter dalam pipa $(\mathrm{m})$

$\mathrm{v}=$ Viskositas kinematik zat cair $\left(m_{2} / \mathrm{s}\right)$

Pada $R_{e}<2300$ aliran bersifat laminer

Pada $R_{e}>4000$ aliran bersifat turbulen

Pada $R_{e}=2300-4000$ terdapat daerah transisi,dimana aliran dapat bersifat laminer dan turbulen tergantung pada kondisi pipa dan aliran.

\subsection{2 kerugian head dalam jalur pipa}

Dalam aliran melalui jalur pipa, kerugian juga akan terjadi apabila ukuran pipa, bentuk penampang, atau arah aliran berubah. Kerugian head di tempat- tempat transisi yang demikian itu dinyatakan secara umum dengan rumus :

$$
h_{f}=f \frac{v^{2}}{2 g}
$$

Dimana: 
$\mathrm{V}=$ Kecepatan rata-rata didalam pipa

$\mathrm{f}=$ Koefisien kerugian

$\mathrm{g}=$ Percepatan gravitasi $\left(9,8 \mathrm{~m} / \mathrm{s}^{2}\right)$

$h_{f}=$ Kerugian head $(\mathrm{m})$

Cara menentukan harga $f$ untuk berbagai bentuk transisi pipa akan diperinci seperti berikut

A. Ujung masuk pipa

Jika"v"menyatakan kecepatan aliran setelah masuk pipa,maka harga koefisien kerugian $f$ dari rumus (2.11) untuk berbagai bentuk masuk pipa seperti diperlihatkan dalam gambar menurut weisbach adalah sebagai berikut:

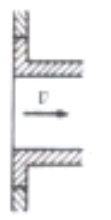

(i)

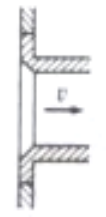

(ii)

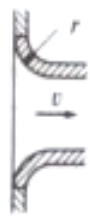

(iii)

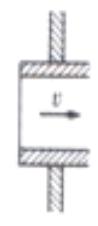

(iv)

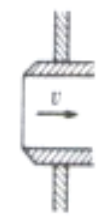

(v)

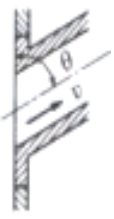

(vi)
Gambar 2.10 Berbagai bentuk ujung masuk pipa ( Sularso Haruo Tahara, p.34 )

(i) $f=0,5$

(ii) $f=0,25$

(iii) $f=0,06$ (untuk $r \quad$ kecil) sampai 0,005(untuk r besar)

(iv) $f=0,56$ (v) $f=3,0$ (untuk sudut tajam)sampai

1,3(untuk sudut $45^{\circ}$ )

(vi) $f=f_{1}+0,3 \cos \theta+0,2 \cos ^{2} \theta$ Dimana $f_{1}$ adalah koefisien bentuk dari ujung masuk dan mengambil harga (i) sampai (v) dengan bentuk yang terpakai.

Bila ujung pipa isap memakai ujung lonceng yang tercelup dibawah permukaan air maka harga $f$ adalah yang diperlihatkan gambar

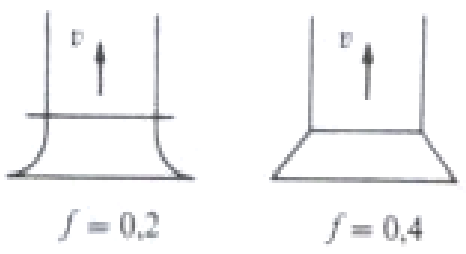

Gambar 2.11 Koefisien kerugian mulut lonceng atau corong pada pipa isap

( Sularso Haruo Tahara, p.34 )

B. Koefisien kerugian pada belokan pipa

Ada dua macam belokan pipa,yaitu belokan lengkung dan belokan patah(miter atau multipiece bend). 
Untuk belokan lengkung sering dipakai rumus fuller dimana $f$ dari pers (2.11) dinyatakan sebagai berikut:

$f=\left[0,31+1,847\left(\frac{D}{2 R}\right)^{3 \prime 2}\right]\left(\frac{\theta}{90}\right)^{0,5}$

Dimana : $D$ : Diameter dalam pipa (m)

$$
R \text { : Jari-jari lengkung sumbu }
$$
belokan (m)

$$
\begin{aligned}
& \theta: \text { Sudut belokan (derajat ) } \\
& f: \text { koefisien kerugian }
\end{aligned}
$$

Hubungan diatas digambarkan dalam diagram seperti diperlihatkan dalam gambar 2.8

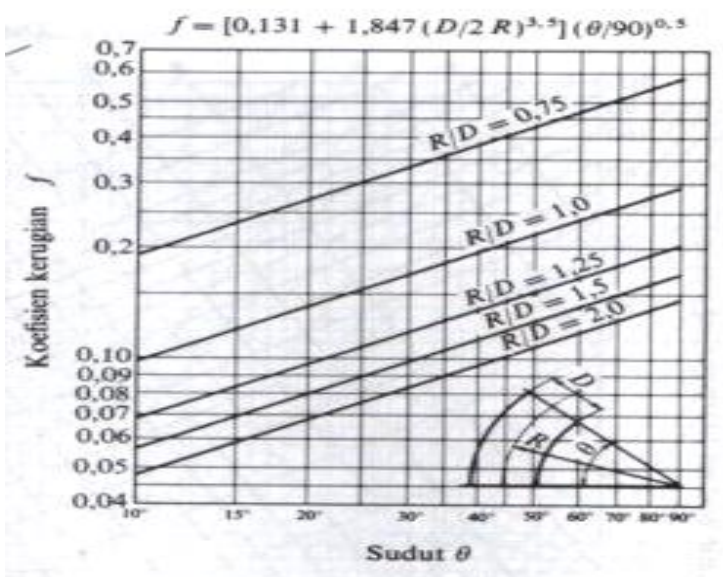

Gambar 2.12 Koefisien kerugian pada belokan ( Sularso Haruo Tahara, p.34 )

Dari percobaan weisbach dihasilkan rumus yang umur dipakai untuk belokan patah sebagai berikut

$$
f=0,946 \sin ^{2} \frac{\theta}{2}+2,047 \sin ^{4} \frac{\theta}{2}
$$

Dimana $\theta:$ Sudut belokan

$$
f: \text { Koefisien kerugian }
$$

\begin{tabular}{|c|c|c|c|c|c|c|c|c|c|}
\hline & $\theta$ & S & 10 & is & 22,5 & 30 & 45 & (x) & 90 \\
\hline 1 & Halus & 0,016 & 0,034 & 0,042 & 0.066 & 0,130 & 0,236 & 0,471 & 1.129 \\
\hline & Kasar & 0,024 & 0,44 & $0,06 ?$ & 0,154 & 0.165 & 0,320 & 0,684 & 1.265 \\
\hline
\end{tabular}

Hubungan antara sudut dan koefisien kerugian diberikan tabel 2.2

Tabel 2.2 koefisien kerugian belokan pipa ( SularsoHaruo Tahara, p.34)

Adapun koefisien kerugian untuk

\begin{tabular}{|c|c|c|c|c|c|c|c|c|c|c|c|}
\hline \multirow{3}{*}{ a } & & $l / D$ & 0,71 & 0,943 & 1,174 & 1,42 & 1,86 & 2,56 & 3,72 & 4,89 & 6,28 \\
\hline & \multirow{2}{*}{$f$} & Halus & 0,507 & 0,350 & 0,333 & 0,261 & 0,289 & 0,356 & 0,356 & 0,389 & 0,399 \\
\hline & & Kasar & 0,510 & 0,415 & 0,384 & 0,377 & 0,390 & 0,429 & 0,460 & 0,455 & 0,444 \\
\hline \multirow{3}{*}{ b } & & $I / D$ & 1,23 & 1,67 & 2,37 & 4,11 & 6,10 & & & & \\
\hline & \multirow{2}{*}{$f$} & Halus & 0,195 & 0,150 & 0,167 & 0,190 & 0,201 & & & & \\
\hline & & Kasar & 0,347 & 0,300 & 0,337 & 0,354 & 0,360 & & & & \\
\hline \multirow{3}{*}{ c } & & $l / D$ & 1,186 & 1,40 & 1,63 & 1,86 & 2,325 & 2,91 & 3,49 & 4,65 & 6,05 \\
\hline & \multirow{2}{*}{$f$} & Halus & 1,120 & 0,125 & 0,124 & 0,117 & 0,096 & 0,108 & 0,130 & 0,148 & 0,142 \\
\hline & & Kasar & 0,294 & 0,252 & 0,266 & 0,272 & 0,317 & 0,317 & 0,318 & 0,310 & 0,313 \\
\hline \multirow{3}{*}{ d } & & $l / D$ & 1,23 & 1,67 & 2,37 & 3,77 & & & & & \\
\hline & \multirow{2}{*}{$f$} & Halus & 0,157 & 0,156 & 0,143 & 0,160 & & & & & \\
\hline & & Kasar & 0,300 & 0,378 & 0,264 & 0,242 & & & & & \\
\hline
\end{tabular}
belokan patah dengan potongan banyak (multipiece) diberikan dalam tabel 2.3

Tabel 2.3 Koefisien kerugian belokan pipa potongan banyak 
C. Kerugian karena pembesaran penampang secara gradual

Dalam hal ini kerugian head dinyatakan sebagai:

$h_{f}=f \frac{\left(v_{1}-v_{2}\right)^{2}}{2 g}$

Dimana : $v_{1}=$ Kecepatan rata-rata dipenampang yang $\operatorname{kecil}(\mathrm{m} / \mathrm{s})$

$$
v_{2}=\quad \text { Kecepatan rata-rata }
$$

dipenampang yang besar $(\mathrm{m} / \mathrm{s})$

$$
\begin{aligned}
f & =\text { Koefisien kerugian } \\
g & =\text { Percepatan gravitasi } 9,8 \mathrm{~m} / \mathrm{s} \\
h_{f} & =\operatorname{Kerugian} \operatorname{Head}(\mathrm{m})
\end{aligned}
$$

Koefisien kerugian untuk pembesaran penampang secara gradual pada penampang berbentuk lingkaran diberikan pada gambar 2.9. Hasil percobaan menunjukan bahwa harga minimum sebesar 0,135 terjadi bila $\theta$ adalah sebesar $5^{\circ}$ sampai $6^{\circ} 30^{\prime}$.Juga untuk penampang bujur sangkar,harga minimum sebesar kira-kira 0,145 terjadi pada $\theta=6^{\circ}$.Harga minimum untuk penampang segi empat sebesar 0,17 sampai 0,18 terjadi pada $\theta=11^{\circ}$.
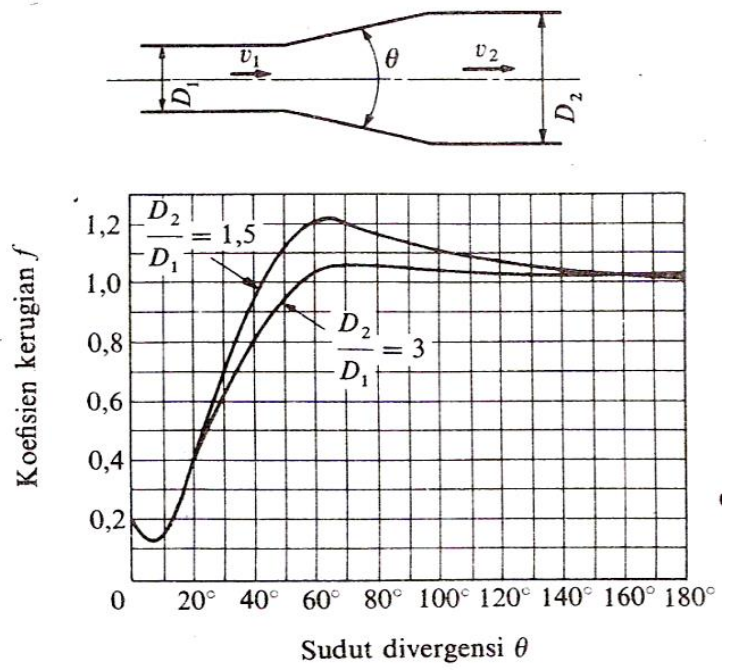

Gambar 2.13 Koefisien kerugian pada pembesaran gradual(bentuk diffuser)

(Sularso Haruo Tahara, p.36)

D. Pembesaran penampang pipa secara mendadak

Untuk kasus ini (gambar 2.10), kerugian head dapat dinyatakan dengan rumus:

$h_{f}=f \frac{\left(v_{1}-v_{2}\right)^{2}}{2 g}$

Dimana $f \approx 1$

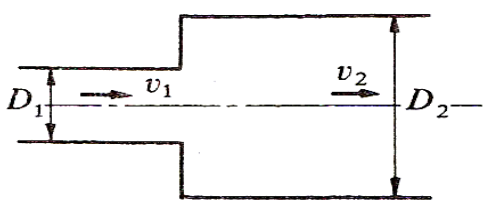

Gambar 2.14 Koefisien kerugian pada pembesaran mendadak 
E. Pengecilan penampang pipa secara mendadak

$h_{f}=f \frac{v_{2}^{2}}{2 g}$

Dimana harga $f$ diberikan pada tabel 2.4

Tabel 2.4 keofisien kerugian bagian pipa dengan pengecilan penampang secara tiba tiba

\begin{tabular}{|l|l|l|l|l|l|l|l|l|l|l|l|}
\hline$\left(D_{1} D_{2}\right)^{2}$ & 0 & 0,1 & 0,2 & 0,3 & 0,4 & 0,5 & 0,6 & 0,7 & 0,8 & 0,9 & 1,0 \\
\hline$f$ & 0,50 & 0,48 & 0,45 & 0,41 & 0,36 & 0,29 & 0,21 & 0,13 & 0,07 & 0,01 & 0 \\
\hline
\end{tabular}

Di: Diantete pipp beat

D): Diameter pipa kectl

1:: Keeppian alran pada pipo kecil (mis)

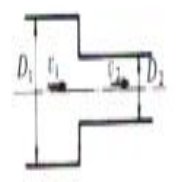

I

( Sularso Haruo Tahara, p.37 )

F. Orifis dalam pipa

Kerugian head untuk orifis diberikan menurut rumus:

$h_{f}=f \frac{v^{2}}{2 g}$

Dimana $v$ adalah kecepatan rata-rata dipenampang pipa. Adapun harga $f$ diberikan dalam tabel 2.5

Tabel 2.5 koefisien kerugian pada orifis dalam pipa

\begin{tabular}{|c|c|c|c|c|c|c|c|c|c|c|c|}
\hline$\left(D_{c} / D\right)^{2}$ & 0 & 0,1 & 0,2 & 0,3 & 0,4 & 0,5 & 0,6 & 0,7 & 0,8 & 0,9 & 1,0 \\
\hline$f$. & $\infty$ & 226 & 47,8 & 17,5 & 7,8 & 3,75 & 1,80 & 0,80 & 0,29 & 0,06 & 0 \\
\hline
\end{tabular}

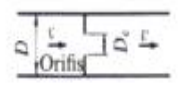

G. Ujung keluar pipa

Kerugian keluar pipa diberikan pada rumus:

$$
h_{f}=f \frac{v^{2}}{2 g}
$$

Dimana $f=1,0$ dan " $v$ " adalah kecepatan rata-rata dipipa keluar

\subsubsection{Kerugian head dikatup}

Kerugian head dikatup dapat ditulis sebagai berikut:

$$
h_{v}=f_{v} \frac{v^{2}}{2 g}
$$

Dimana : $v:$ Kecepatan rata-rata dipenampang masuk katup(m/s)p

$$
\begin{aligned}
& f_{v}: \text { Koefisien kerugian katup } \\
& h_{v}: \text { Kerugian head } \operatorname{katup}(\mathrm{m})
\end{aligned}
$$

Harga $f_{v}$ untuk berbagai jenis katup dalam keadaan terbuka penuh diberikan dalam tabel 2.6. Adapun hubungan antara derajat pembukaan koefisien gesekan katup-katup utama,diberikan dalam gambar 2.11 
Tabel 2.6 koefisien kerugian dari berbagai katup
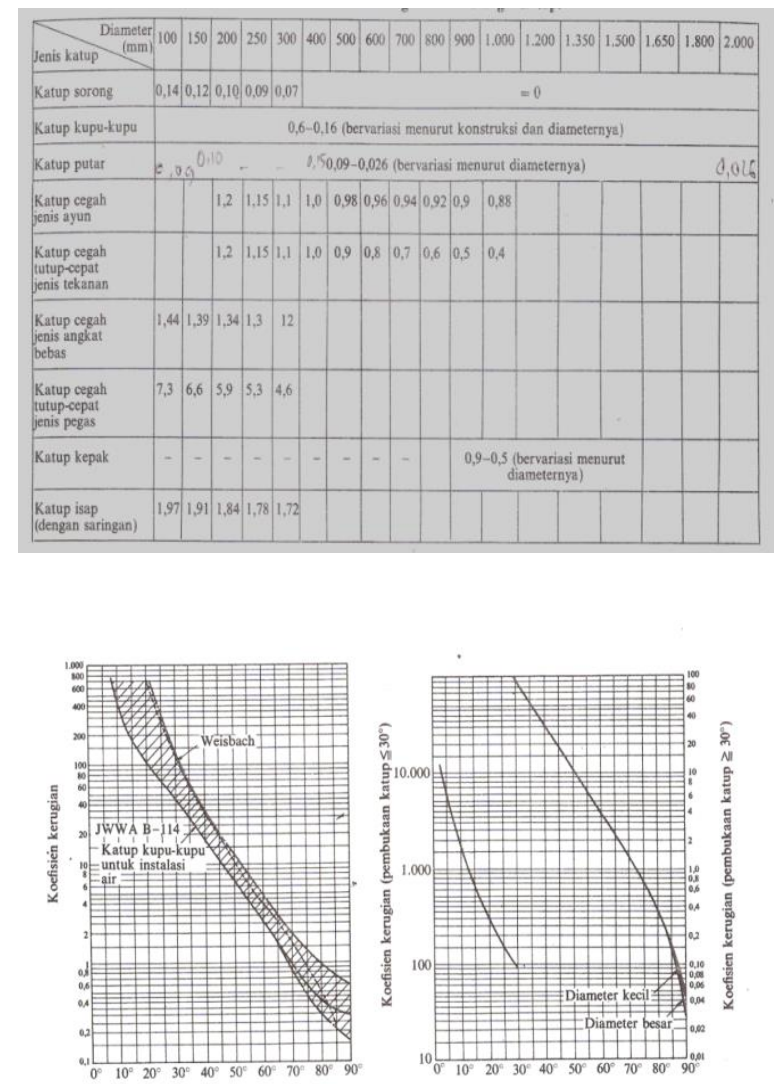

Gambar 2.15 Pembukaan katup dam koefisien kerugian pada katup-katup utama (Sularso Haruo Tahara, p.39)

\subsection{Daya Nominal Penggerak $\operatorname{Mula}\left(P_{m}\right)$}

Meskipun daya poros,daya nominal dari penggerak mula yang dipakai untuk menggerakan pompa harus ditetapkan dari rumus :

$P_{m}=\frac{P(1+\alpha)}{\eta_{t}}$
Dimana $P_{m}$ : Daya nominal penggerak mula $(\mathrm{kW})$

$$
\begin{aligned}
& \alpha \quad: \text { Faktor cadangan (pecahan) } \\
& \eta_{1}: \text { Efisiensi transmisi (pecahan) }
\end{aligned}
$$

Jika titik kerja sebuah pompa bervariasi dalam suatu daerah tertentu, maka daya poros biasanya juga bervariasi. Jadi daya nominal harus ditentukan untuk daya poros maksumimum $P$ dalam daerah kerja normal dengan menggunakan pers.(2.18)

Tabel 2.7 Faktor cadangan dan efisiensi transmisi

\begin{tabular}{|l|l|c|}
\hline \multicolumn{2}{|c|}{ Jenis transmisi } & $\mathrm{n}_{1}$ \\
\hline \multicolumn{2}{|l|}{ Sabuk rata } \\
Sabuk - V & $0,93-0,93$ \\
\hline $\begin{array}{l}\text { Roda } \\
\text { gigi }\end{array}$ & Roda gigi lurus satu & 0,95 \\
& $\begin{array}{l}\text { tingkat } \\
\text { Roda gigi miring } \\
\text { satu tingkat } \\
\text { Roda gigi kerucut } \\
\text { satu tigkat } \\
\text { Roda gigi planiter }\end{array}$ & $0,9,95-0,98$ \\
& $0,92-0,96$ \\
satu tingkat & $0,92-0,98$ \\
\hline \multicolumn{2}{|l|}{ Kopling hidrolik } & $0,95-0,97$ \\
\end{tabular}




\begin{tabular}{|c|c|}
\hline Jenis penggerak mula & $\alpha$ \\
\hline Motor induksi & $0,1-0,2$ \\
\hline Motor bakar kecil & $0,15-0,25$ \\
Motor bakar besar & $0,1-0,2$ \\
\hline
\end{tabular}

\section{Metedologi penelitian}

\section{Proses penelitian}

\section{Tempat dan waktu penelitian}

\section{a. Tempat penelitian}

untuk menganalisis dan untuk mencapai hasil dari penelitian dalam mencari dan mengambil data dimana kegiatan ini dilakukan langsung dari lapangan yaitu di area painting

\section{b. Waktu penelitian}

\section{Tabel Jadwal Penelitian}

\begin{tabular}{|c|c|c|c|c|c|c|c|}
\hline \multirow{2}{*}{ No. } & \multirow{2}{*}{ Kegiatan } & \multicolumn{5}{|c|}{ Waktu Pelaksanaan } \\
\cline { 5 - 8 } & & April & Mei & Juni & Juli & Agustus & September \\
\hline 1 & Survei & & & & & & \\
\hline 2 & Pendahuluan & & & & & & \\
\hline 3 & Penyusunan & & & & & & \\
\hline 4 & Pnalisa Data & & & & & & \\
\hline 5 & Penosal & & & & & & \\
& Laporan & & & & & & \\
\hline
\end{tabular}

\section{Pengambilan data}

Pengambilan data yang diakukan dalam penelitian ialah dilapangan dalam perhitungan semua kejadian sebagai data awal dan data-data pendukung sebagai dasar analisa permasalahan:

1. Data lapangan

Berupa yang berada dilapangan seperti perpipaan,perhitungan pipa yang diperlukan dalam menentukan spesifikasi kebutuhan pompa.yang diperlukan adalah:

- Panjang pipa

- Diameter luar dan dalam

- Banyaknya belokan

- Sudut belokan,dll.

2. Peralatan yang digunakan

Peralatan yang dipergunakan dalam melakukan penelitian yang dilakukan ialah peralatannya yaitu:

\section{Jangka Sorong/Vernier Caliper}

Jangka sorong adalah alat ukur yang digunakan dengan cara digeser, ketelitiannya dapat mencapai seperseratus milimeter terdiri dari dua bagian,bagian diam dan bagian yang bergerak

2. Meteran 
Meteran adalah suatu alat ukur yang digunakan untuk mengukur ketinggian dan panjang suatu benda, biasanya dipakai pada bidang industri, pabrik, pembangunan dsb.

\section{Hasil dan pembahasan}

Tabel 4.1 Hasil perhitungan dan spesifikasi

\begin{tabular}{|l|l|c|c|}
\hline NO & Keterangan & $\begin{array}{l}\text { Perhitungan } \\
\text { teoritis }\end{array}$ & $\begin{array}{l}\text { Spesifikasi } \\
\text { pompa }\end{array}$ \\
\hline 1 & $\begin{array}{l}\text { Head Total } \\
\text { Pompa (H) }\end{array}$ & 12,017 & 25 \\
\hline 2 & $\begin{array}{l}\text { Kapasitas } \\
\text { Pompa (Q) }\end{array}$ & $\begin{array}{c}0,25 \\
\mathrm{~m}^{3} / \mathrm{min}\end{array}$ & $\begin{array}{c}0,25 \\
\mathrm{~m} / \mathrm{min}\end{array}$ \\
\hline 4 & $\begin{array}{l}\text { Kecepatan } \\
\text { Spesifikasi } \\
\left(\eta_{s}\right)\end{array}$ & $\begin{array}{c}100,70 \mathrm{~m}^{2} / \\
\min \end{array}$ & - \\
\hline 5 & $\begin{array}{l}\text { Efisiensi } \\
\text { Pompa }\left(\eta_{p}\right)\end{array}$ & $70 \%$ & - \\
\hline 6 & $\begin{array}{l}\text { Daya Air } \\
(P \mathrm{w})\end{array}$ & 1,01 & - \\
\hline 7 & $\begin{array}{l}\text { Head Statis } \\
\text { Pompa }\left(h_{a}\right)\end{array}$ & 2 & - \\
\hline 8 & $\begin{array}{l}\text { Daya poros } \\
(P), \mathrm{kW}\end{array}$ & 1,44 & - \\
\hline 9 & $\begin{array}{l}\text { Daya } \\
\text { Nominal } \\
\text { Penggerak } \\
\text { Mula }\end{array}$ & $1,87 \mathrm{~kW}$ & $12 \mathrm{~kW}$ \\
\hline
\end{tabular}

Jurnal Kajian Teknik Mesin

Vol. 2 No. 1 April 2017 yang di lapangan

\section{Pembahasan}

Dari perhitungan diperolh bahwa : Head teoritis dalah sebesar 12,017 m sedangkan yang ada dilapangan sebesar 25 yang dihitung dengan kapasitas yang sama $0,25 \mathrm{~m} / \mathrm{min}$, dan daya motor penggerak teoritis $1,87 \mathrm{~kW}$ sedangkan yang tepasang dilapangan $12 \mathrm{~kW}$ perbedaannya jauh. Hal tersebut dimaksudkan untuk mengatasi fluktuasi head dan fluktuasi beban.

\section{Kesimpulan dan Saran}

1. kesimpulan

Dari data hasil perhitungan dan pembahasan sebelumnya, maka dapat kesimpulan bahwa hal yang berkaitan dengan kinerja pompa sirkulasi adalah kapasitas aliran ( debit, Q $\mathrm{m}^{2} / \mathrm{min}$ ), Head Total ( $\mathrm{H}$, meter ) dan Daya motor penggerak $(\mathrm{P}, \mathrm{kW})$ dari hasil perhitungan diperoleh:

1. Daya motor nominal teoritis $(\mathrm{P})$ penggerak pompa adalah : 1,8 kW sedangkan yang ada dilapangan : 12 $\mathrm{kW}$

2. Head total pompa $(\mathrm{H})$ teoritis adalah : 12,017 m sedangkan yang ada dilapangan : $25 \mathrm{~m}$ 
Selisih besarnya Daya motor penggerak dan Head Total antara teoritis dan yang ada dilapangan untuk antisipasi fluktuasi head.

2. Saran

Dari pembahasan dan data-data diatas bahwa pompa yang sudah tertera harus diperhatikan:

a) daya dan head pompa karena kebutuhan pompa untuk sirkulasi terkadang bisa meningkat dan juga.

b) Instalasi pemipaan juga harus diperhatikan agar laju aliran fluida bisa berjalan lancar.

\section{DAFTAR PUSTAKA}

1. Carl George Da laval.(2013).

Centrifugal Pumping Machinery,

The Theory and Practice of

Centrifugal and Turbin. Published

Forgotten books 2013.

2. Dietzel, Fritz.(2005).Turbin, Pompa, dan Kompresor.Jakarta:Erlangga

3. Edward, Hicks.Teknologi Pemakain

Pompa.Ciraca,Jakarta: Erlangga

4. Handi Sutrisno.(2010). Aplikasi Sig

Dengan Arcview 3.3 Untuk Simulasi

Perancangan Pipa di PDAM Tirta
Moedal Kota Semarang Zona Bukit

Sari.

5. Jurnal Fema.(Januari 2013). nomor 1 , volume 1

6. Suprihatin, Ono Suparno.(2013).

Teknologi Pengolahan Air. (penerbit

Kampus IPB Taman Kencana

Bogor,)

7. Sularso, Haruo Tahara.(2004).

Pompa dan

Kompresor.Jakarta:Pratnya Paramita. 
Jurnal Kajian Teknik Mesin

Vol. 2 No. 1 April 2017 